\title{
INTERESES QUE MOVILIZAN A LA COMUNIDAD DIGITAL DE CHANGE.ORG: MÁS ALLÁ DE LO POLÍTICO
}

\section{INTERESTS THAT MOBILIZE THE CHANGE.ORG DIGITAL COMMUNITY: BEYOND THE POLITICAL}

\author{
Andrea Leticia Quintana Pujalte \\ Universidad de Málaga, España \\ (D) https://orcid.org/0000-0002-1834-283X
}

\section{Ana Almansa-Martínez}

Universidad de Málaga, España

(D) https://orcid.org/0000-0003-0256-6369

Autor para correspondencia: Andrea Leticia Quintana Pujalte, email: 1.quintanapujalte@uma.es

\section{Resumen}

Los movimientos populares tomaron un renovado impulso con la consolidación de las nuevas tecnologías y el surgimiento de plataformas públicas y privadas, que sirven como canal para las protestas sociales y la defensa de intereses ciudadanos. Desde un método de análisis de contenido cualitativo, se examinan las veinte peticiones más exitosas en la historia de la plataforma privada Change.org en cuatro países: Estados Unidos, Reino Unido, Francia y Australia. Se observa cómo operan estas campañas, y se identifican los intereses que motivaron la participación de su comunidad digital. A pesar de que el impacto de la participación política online es un tema de debate en la literatura cientifica, los resultados evidencian similitudes en el tipo de temáticas que se defienden a nivel transnacional en Change.org, y sugieren que existirían peticiones externas al campo estrictamente político que movilizan de modo transversal a la ciudadanía en el campo digital.

Palabras clave: ciberactivismo, comunicación digital, participación ciudadana, Change.org, plataformas.

\footnotetext{
Abstract

Popular movements took a renewed momentum with the consolidation of new technologies and the emergence of public and private online platforms, which serve as a channel for social protests and the defense of civic interests. From a qualitative content analysis, the twenty biggest "victories" in the history of the private platform Change.org are examined in four countries: United States, United Kingdom, France and Australia. It is observed how these campaigns operate, and the interests that have motivated the participation of their digital community are identified. Despite the fact that the impact of online political participation is an issue that it is still on debate in
} 
the scientific literature, the results show similarities in the type of interests that are defended transnationally on Change.org, and suggest that there ${ }^{o}$ would be requests outside the strictly political field that mobilize citizens in a transversal way.

Keywords: cyber-activism, digital communication, civic participation, Change.org, platforms.

Recibido: 09/03/2021

Aceptado: 25/04/2021

\section{Introducción}

El proceso de consolidación de Internet como una poderosa herramienta de comunicación incluye profundas transformaciones de los usos y apropiaciones por parte de los usuarios. El nuevo paradigma tecnológico señalado por Castells (1996, $2002,2007,2009)$ impacta en varios aspectos de las relaciones sociales, y de modo particular, en las atravesadas por la comunicación y la política. Como señala el autor, "las relaciones de poder están cada vez más moldeadas por el campo de la comunicación" (Castells, 2007, p. 239).

La comunicación consolida la participación en los espacios públicos políticos, y contribuye principalmente en la construcción del perfil de los ciudadanos, ya que en la toma de la palabra y en la participación, el sujeto construye su ciudadanía (Mouffe, 1999, 2007, 2013). El rol de las herramientas digitales que apuntan a la participación en la esfera pública se vuelve crucial entonces para el desarrollo de ese proceso (Lizaso et al., 2018; Van Dijck, 2013), y lograr así instalar otros discursos que podrían ser considerados contra-hegemónicos o de resistencia (Salazar-Torres, 2017).

Desde este enfoque, este estudio plantea un análisis sobre la participación de la comunidad digital de la plataforma abierta, comercial y con fines de lucro denominada Change.org. Para problematizar la cuestión de la participación se toman aquellas campañas que han tenido una mayor cantidad de adhesiones por parte de los usuarios en cuatro países (Estados Unidos, Francia, Reino Unido y Australia) en la historia de la plataforma. El estudio también plantea los debates vigentes sobre la participación online, y propone una mirada singular sobre los aspectos detectados en el análisis, lo que lleva a discutir sobre los intereses que movilizan a esta comunidad en particular.

\section{Marco teórico}

El impacto que tienen las nuevas tecnologías en la participación ciudadana cobra tal importancia que, ya hace dos décadas, Castells (2000) consideraba que los nuevos movimientos sociales de la sociedad red

Global Media Journal México, 18(34), 111-136, enero - junio 2021. 
se constituyen y sostienen a partir de identidades colectivas interclasistas que se diferencian de los primeros movimientos sociales por el uso $\mathrm{y}$ apropiación que realizan de las herramientas digitales. Estas les permiten potenciar las actividades de protesta, buscar adhesiones a las demandas e interpelar a la ciudadanía para que sean parte de los procesos de transformación que exigen (Della Porta y Diani, 2011; Della Porta y Tarrow, 2005; Mendes y Araújo, 2013; Papacharissi, 2002, 2009; Sabariego, 2016; Treré, 2016). En este camino dan paso al surgimiento de nuevas formas de movilización y activismo ciudadano (Cotino-Hueso, 2011; Montero y Sierra, 2016).

En el escenario digital los modos de participación, adhesión y protesta se renuevan y adaptan a los beneficios que ofrece Internet como canal de difusión y propagación de ideas y posicionamientos. Este territorio abierto permite que cualquier individuo pueda formar parte de la producción, adhesión y difusión de contenidos (Koenig y McLaughlin, 2018). Los espacios de comunicación digitales empoderan a la ciudadanía y potencian la posibilidad de que se constituyan como un contrapoder (Castells, 2012; Jenkins, 2006; Sampedro, 2014). Ejemplo de ello fueron los movimientos que irrumpieron en la arena pública a nivel global, como la Primavera Árabe, Occupy Wall Street o el movimiento español 15M, nacido en 2011. Respecto del último mencionado, Fernández-Prados (2012) destaca el uso de las redes sociales para la organización "asamblearia, horizontal y altamente

\footnotetext{
${ }^{1}$ En España se pueden hallar Change.org, HazteOir.org,
} Oiga.me, Irekia, Peticiones.org o Petición Pública, o participativa" (p. 632), lo que lo lleva a denominar a este tipo de activismo 2.0, frente a movilizaciones previas a la consolidación de estas plataformas, denominadas 1.0.

Estas acciones no se originan sólo a partir de la toma de la palabra en redes sociales, sino también desde la participación en plataformas ciudadanas que constituyen verdaderos "perros guardianes" de los procesos democráticos. Estos espacios que se organizan en la esfera digital forman parte de una lógica de empoderamiento ciudadano que se manifiesta de modo complejo en las sociedades postmateriales (Inglehart, 1997).

Las demandas por parte de ciudadanos hacia instituciones gubernamentales, que a través de la firma de peticiones muestran su voluntad o sus preocupaciones sobre aspectos de la agenda política, tienen ya larga data en el escenario político. Desde hace algunos años, cuentan además con su correlato en el escenario digital en diversas plataformas. La participación ciudadana es un indicador de la voluntad de exigir cambios en los procesos democráticos de toma de decisiones (Millard et al., 2012).

Como indica Pérez-Escolar (2019), las plataformas ciudadanas pueden ser de peticiones online $^{l}$, de las que a nivel global se pueden hallar variedad de ejemplos. Alonso-Muñoz y CaseroRipollés (2017) estudian el caso de las plataformas digitales españolas "vinculadas a la sociedad civil basadas en la transparencia y orientadas a la monitorización de los centros de poder" (p. 1351) e

plataformas de iniciativas legislativas populares, como Mifirma.com. 
identifican cinco tipos según la dimensión de transparencia que cubren: plataformas de rendición de cuentas; plataformas de conectividad política y social, en que la ciudadanía puede ser partícipe del debate de proyectos de ley; de periodismo colaborativo; de fomento del debate y discusión pública que buscan el diálogo y la tolerancia; y plataformas de gobierno abierto.

Otros estudios que abordan las plataformas públicas de peticiones en línea se preocupan por conocer de qué modo se asegura la privacidad de quien firma la petición, y la veracidad de esta acción. Ejemplo de estas investigaciones se realizaron en el Parlamento de Queensland (Grover, 2016), en la Cámara de los Comunes de Reino Unido (Maer, 2010) o en el Bundestag alemán (Lindner y Riehm, 2009), entre otros. En el ámbito hispanoparlante, Calvo (2016) se enfoca en la plataforma privada Change.org y su modelo de negocios, para conocer si se adapta a la legislación española. Concluye que la plataforma está alejada del derecho de petición español, con un sistema de testeo laxo y que basa sus beneficios en el coste por adquisición.

El presente estudio realiza un abordaje sobre las peticiones exitosas publicadas en la plataforma privada Change.org. Se examinan aquellas campañas que defienden intereses en el territorio digital, y que lograron las más altas adhesiones de los usuarios en la historia de la plataforma, las cuales ocurrieron en Estados Unidos, Reino Unido, Francia y Australia. Desde un abordaje cualitativo se analizan los elementos que constituyen las campañas y se consideran las modalidades de los movimientos populares y participación ciudadana perceptibles en una plataforma de origen privado.

\section{Ciberactivismo y movimientos populares}

Distintos autores se han preocupado por dar una definición a las nuevas formas de protesta atravesadas por las Tecnologías de la Información y la Comunicación. Entre las perspectivas teóricas se pueden encontrar definiciones como ciberactivismo, activismo en línea, hackctivismo, desobediencia civil electrónica, entre otras, que expresan las distintas formas en que los activistas y sus organizaciones manifiestan y desarrollan sus acciones a través de la red (Jordan, 2002).

Hace dos décadas, Denning (2001) distinguía tres tipos de actividades que tienen por objetivo emplear Internet como herramienta para influir en la política: activismo digital, hacktivismo y ciberterrorismo. El activismo digital o ciberactivismo se refiere al uso no destructivo de Internet para difundir, promocionar o defender una causa u objetivo. El hacktivismo o desobediencia civil electrónica combina el activismo con el hackeo, como puede ser el bloqueo de páginas, la alteración de contenidos de una página web (hacking), o la transmisión de virus que destruyen un sistema (cracking). Un claro ejemplo de este tipo de activismo es el caso de WikiLeaks, organización que ha difundido informaciones de alta sensibilidad para la imagen de organizaciones y gobiernos poderosos. $\mathrm{Su}$ salto a la fama internacional se dio en 2010 cuando difundió un video de un ataque en Bagdad contra civiles desde dos helicópteros 
estadounidenses en el que doce personas fueron asesinadas. A partir del escrutinio público, la organización pretende consolidar la democracia (Feenstra y Casero-Ripollés, 2014).

El ciberterrorismo es la convergencia entre ciberespacio y el terrorismo. Esta clasificación hecha por Denning busca comprender el activismo digital desde un menor a un mayor grado de violencia (Fernández-Prados, 2012). Algunos autores se declaran en contra de esta gradación, al afirmar que sostiene un sesgo desinteresado por casos de extrema importancia para los derechos ciudadanos, como lo es el terrorismo.

El estudio que aquí se presenta defiende la perspectiva del ciberactivismo como "una de las herramientas más importantes para inducir, de manera horizontal, ciertas transformaciones en la sociedad red" (Marqués-Pascual, 2015, p. 884). Autores como González-Bailón et al. (2017) o Cotarelo y Crespo (2012) estudian la irrupción de las protestas políticas y las temáticas que las movilizan, especialmente potenciadas en Twitter y Facebook. Sierra Caballero (2020) se preocupa por comprender, desde un enfoque crítico, las mediaciones de la tecnología desde lo político, y la construcción de lo que denomina espacio público oposicional. Varios autores han constatado que la promoción, difusión y apoyo a causas surgidas en estos espacios de participación tienen el poder de trascender de la red, para tener un impacto real en las decisiones políticas (Bennett et al., 2008).

Feenstra y Casero-Ripollés (2014) son categóricos en este sentido: "las tecnologías digitales, particularmente las redes sociales, podrían no solo mejorar la organización, coordinación, agregación, orquestación, movilización y globalización de las acciones ciudadanas, como las protestas, sino que también podrían generar nuevas modalidades de comportamiento político" (p. 2449).

Los autores se preocupan por identificar de qué modo las tecnologías sirven como espacios de vigilancia del sistema político por parte de la ciudadanía. Identifican cuatro modalidades de monitoreo cívico: la función de vigilancia, la extracción y filtración de información secreta, la expansión de problemas a través del periodismo alternativo y la extensión de la representación más allá de los parlamentos. Esta categorización sirve de base para el análisis que se propone en este estudio, en el que se hará foco especialmente en cómo se traduce la participación ciudadana más allá de los espacios institucionalizados.

La problematización de la participación política en escenarios digitales inspira debates desde hace más de dos décadas. Como indica Dahlgren (2018), no se pueden generar aún consensos respecto del impacto de las nuevas tecnologías en el ámbito político y en la participación ciudadana: "la red afecta todas las fases de la vida personal, organizativa e institucional. Esto significa que se ha convertido en una fuerza dominante en la construcción del mundo moderno contemporáneo" (p. 26). El autor considera que desde los medios digitales se hace política de diferentes formas, sin romper totalmente con prácticas políticas del pasado.

Por otro lado, algunas investigaciones señalan una postura menos optimista respecto de los verdaderos alcances para la participación, 
movilización y transformación política de los ciudadanos desde los espacios digitales (Bimber, 2001; Christensen, 2011; Glenn, 2015; Hindman, 2009; Morozov, 2009, 2012; Scheufele y Nisbet, 2002; Shulman, 2005).

La crítica más dura que realizan es que son tecnologías que no implican una participación real de la ciudadanía porque su apoyo es superfluo, y sólo genera bienestar individual, sin impacto en la vida real. Desde este enfoque se denomina peyorativamente como slackactivismo a la participación que deviene de la holgazanería en la que el individuo no se involucra personalmente en las causas que apoya (Morozov, 2009, 2012; Skoric, 2012). Ejemplos de ello son acciones que los usuarios pueden apoyar a través de Facebook o Twitter en defensa de ciertos intereses, pero casi sin esfuerzo. También son consideradas acciones de slackativismo la adopción de un marco en el perfil de redes sociales para defender una causa o incluso la firma de una petición online que luego es compartida en perfiles personales (Kristofferson et al., 2014). "La crítica slacktivista sugiere que esta exhibición altamente pública de indignación permite que las personas sientan que están logrando algo, cuando realmente ningún impacto está ocurriendo" (Minocher, 2019, p. 624).

El debate teórico está abierto, sin embargo, siguiendo a Lizaso et al. (2018) se entiende que “quizás debamos eliminar la dicotomía offline online en el convencimiento de que tan real es un tipo de entorno como el otro, y que ambos pueden tener efectos contrastables en el día a día de las personas" (p. 562). Por ello, la postura que se propone desde este estudio es la comprensión de que la participación de la ciudadanía en las causas que se defienden desde los espacios digitales tiene impacto en el espacio público político, y son síntoma de causas que movilizan no sólo a dar apoyo con un clic, una firma o compartiéndolo en redes sociales, sino también abanderándose en causas transversales de carácter social y político. Además, estos microactos de los individuos indicarían una forma más amplia de opinión pública que tienen un impacto político potencial (Margetts et al., 2015). En esta misma línea se adscriben investigaciones como las de Lee y Hsieh, (2013) o Parigi y Gong (2014).

La participación política puede ser observada en la esfera pública, y a través de las herramientas propias de la esfera digital, porque como afirma Dahlgren (2018),

podemos decir que la participación implica intervención en lo político, en las relaciones de poder, independientemente de cuán remotas (o mediadas) sean. Siempre involucra algún tipo de confrontación o lucha, aunque solo sea una discusión. Sin duda, algunos aspectos de lo político forman parte de la política electoral e implican toma de decisiones o elecciones, pero es fundamental que tengamos en cuenta este sentido amplio y extraparlamentario de lo político (p. 28).

Bajo esta premisa, en este escenario atravesado por las tecnologías digitales, los individuos tienen diferentes opciones para promocionar, difundir y 
participar de distintas causas, tanto desde redes sociales generalistas como desde plataformas digitales específicas. Las acciones de softactivismo o clickactivismo posibles en la red se traducen como el apoyo a determinadas cuestiones, generalmente sociales, a través de plataformas en Internet (Marqués-Pascual, 2015). Estas acciones son relevantes en el contexto actual porque empoderan a la ciudadanía para dar sus pareceres respecto de temáticas que los implican, o les interesan.

Para conocer cómo opera la comunicación para la promoción y adhesión de problemáticas sociales movilizadas desde los espacios digitales por ciudadanos que comparten intereses, se considera el enfoque teórico de los movimientos populares (Chadwick, 2008; Dumitrica y Felt, 2020; Escobar, 1992; Howard, 2005; Klotz, 2007; Lilleker et al., 2014; Norris, 2001, 2002, 2007). Estos pueden constituirse alrededor de problemas que, una vez resueltos, provocan su evaporación, aunque también se da el caso de que "otros duran más tiempo, convirtiéndose en organizaciones permanentes; algunos de ellos lideran la formación de importantes movimientos regionales" (Escobar, 1992, p. 421).

Las acciones de los movimientos populares desde las bases son esencialmente localistas, aunque pueden ramificarse horizontalmente -compartiendo información, experiencias y apoyo real con otras luchas-o verticalmente -desde abajo hacia arriba y desde la periferia al centro-. Sus intereses y luchas son pluralistas, comparten una desconfianza hacia la política organizada y las organizaciones políticas convencionales. No conciben su lucha en términos puramente económicos, sino que tienen cierta conciencia de que los problemas y las estructuras de poder locales tienen una relación importante con las estructuras macro (Escobar, 1992).

Espinoza (2011) propone considerar la interacción entre los espacios locales y supralocales, lo cual impacta en la forma y contenidos discursivos de los actores, redefiniendo y reposicionando sus identidades y sus estrategias de acción política. Respecto de ello, el tipo de intereses y temáticas que movilizan a la ciudadanía específicamente desde los espacios digitales ha sido estudiado desde varios enfoques (Casero-Ripollés, 2017; Shirky, 2011; Van Dijck, 2013), y resulta a su vez un elemento relevante a ser identificado para conocer cuáles son los contenidos que tienden a movilizar la protesta (Ruiu y Ragnedda, 2017).

Feenstra y Casero-Ripolles (2014) observan que en el monitoreo cívico que tiene como objetivo la movilización de la ciudadanía desde espacios de representación más allá de la representación política clásica:

el monitoreo abarca tanto la defensa de los intereses ciudadanos que han sido olvidados por los principales partidos políticos como el escrutinio de las actividades de los centros de poder para denunciar públicamente abusos como corrupción politica, beneficios excesivos, ausencia de canales efectivos para la participación ciudadana, falta de transparencia informativa, manipulación de los medios e introducción de lobbies económicos en la política. Además de elaborar y publicar propuestas, este tipo de 
monitoreo también incluye una observación cuidadosa del proceso de toma de decisiones politicas llevado a cabo por los gobiernos y parlamentos y la expresión de desacuerdo cuando sea necesario (p. 2460).

En esta línea de ideas, este estudio plantea conocer cuáles son las temáticas que se defienden en las peticiones de la plataforma abierta, comercial y con fines de lucro, como es Change.org, y que han obtenido una mayor cantidad de apoyo y adhesión (con la cantidad de firmas digitales) de parte de la ciudadanía. Para ello, desde el enfoque teórico sobre movimientos populares y el escenario digital que se ha desarrollado, se aborda la problemática de la participación ciudadana atravesada por la tecnología, en tanto materia de permanente cambio y desarrollo en la actualidad.

\section{Sobre Change.org}

La plataforma Change.org nació en 2007 y es el sitio en línea más conocido a nivel mundial para peticiones electrónicas (Geron, 2012; Koenig y McLaughlin, 2018). Genera campañas de movilización y apoyo que surgen desde los intereses de los ciudadanos, quienes a través de la página web realizan una denuncia que busca sumar adeptos para generar cambios o presionar a representantes de gobierno o empresas. Opera frecuentemente

\footnotetext{
${ }^{2}$ En el caso de España, se fusionó con la hispana Actuable en 2010 y logró posicionarse en el país gracias a esa operación.
}

aliándose con entidades que realizan actividades similares en otros países ${ }^{2}$.

A pesar de contar con el dominio "org" la plataforma es una empresa con fines de lucro. Sus características la posicionan en un sector en el que, a partir de su modelo de negocios, recauda información de potenciales contribuyentes a causas que llevan adelante organizaciones no gubernamentales reales en el mundo; a su vez, disponen de tarifas para patrocinar ciertas campañas de ciertos usuarios. Su fortaleza está en la facilidad para que la comunidad digital genere campañas a partir de un diseño simple e intuitivo. Sin embargo, se evidencian escasos niveles de posibilidad de deliberación por parte de los usuarios entre sí y con el equipo que gestiona la plataforma (Calvo, 2017).

La plataforma cuenta con 329,495,413 usuarios y tiene presencia en más de 196 países, tomando un papel protagónico en lo que a sitios de peticiones online se refiere. Está disponible en doce idiomas y tiene equipos que operan a nivel local en dieciocho países. Además, cuenta con 139 mil socios que aportan entre cinco, diez, quince y veinte euros según sus posibilidades (Change.org, 2020). Estas cifras la convierten en la mayor plataforma virtual de peticiones a nivel mundial.

Según un informe de impacto (Change.org, 2020) los usuarios se contabilizan de a millones, ostentando la mayor cantidad de usuarios en Estados Unidos (75M), seguido por India (21M), Brasil (26M), Reino Unido (17M), Rusia (15M), España 
(14M), Francia (12M), Turquía (12M), México $(12 \mathrm{M})$, Indonesia (10M), Italia (9M), Argentina $(8 \mathrm{M})$, Australia y Canadá (7M cada uno), Alemania (6M), Colombia (4M), Tailandia (3M) y Japón (2M). En otros países sin personal sobre el terreno, cuentan con $62 \mathrm{M}$ de usuarios.

El impacto que tienen este tipo de plataformas hace emerger nuevos interrogantes sobre sus usos y apropiaciones por parte de la ciudadanía, que dan soporte a su existencia tanto dentro como fuera del territorio digital. La presencia de Change.org a nivel global y su alta densidad de usuarios la convierte en un espacio apto para la observación de diversos fenómenos sociales, y es especialmente relevante para el campo de la comunicación. Estudios recientes como el de Arias y Jiménez-Gómez (2020) validan este interés. En su investigación observan las peticiones que se realizaron en Change.org enfocadas en el medioambiente, una temática de gran relevancia, ya que como señalan los autores, de los diecisiete Objetivos de Desarrollo Sostenible de la ONU, siete hacen referencia a cuestiones medioambientales. El objetivo es establecer una metodología de análisis de campañas que pueda ser extrapolable a otras plataformas. Se enfocan en conocer el porcentaje de campañas sobre la temática medioambiental para poder ponderar la importancia de éstas en el conjunto global de peticiones ciudadanas en la plataforma, y evaluar además la capacidad de movilización que logran estas temáticas específicas. Para este último punto, cruzan datos entre la cantidad de firmas que obtuvo cada petición y el número de peticiones distintas pero que forman parte de la misma campaña internacional, o los medios externos que informa cada campaña (sitios web propios, lista de apoyos, organizaciones firmantes $\mathrm{o}$, incluso, gabinete de prensa). El estudio se complementa con un análisis discursivo de cada petición.

Una mirada alternativa a los procesos que se dan en Change.org la ofrecen Mellon et al. (2017). Desde un abordaje metodológico de estudio de caso, observan el modo en que se da la participación online en la plataforma, pero estratificada por género. Realizan una comparación de la agenda temática en diferentes etapas: creación de petición, firma, y éxito. Identifican las preferencias de los creadores de peticiones masculinas y femeninas, para comprender si las preferencias por cuestiones de género se traducen en resultados del proceso de petición. Entre sus hallazgos se destaca que las mujeres están bien representadas en la firma de peticiones, pero están subrepresentadas en la creación de peticiones. De un universo de 3.9 millones de firmas o adhesiones, concluyen que las mujeres firman más peticiones que los hombres, en general.

Otro abordaje sobre la plataforma lo ofrecen Pérez-Escolar et al. (2020), quienes desde una metodología cuantitativa analizan 304 peticiones relacionadas con la cultura popular, publicadas en Change.org de España. El objetivo es explorar sobre el activismo cultural en el que participan las audiencias de la plataforma. El estudio indica que el éxito de las peticiones relacionadas a productos de la cultura popular en la plataforma es escaso, y sólo el $10.6 \%$ tiene éxito. En términos comparativos, las peticiones iniciadas por fans, antifans y trolls son igualmente populares, lo que sugiere que 
"Change.org no es un sitio ideal para el ciberactivismo porque no ofrece mecanismos para filtrar y eliminar información. Además, la interactividad entre usuarios no es fomentada, y tampoco se utilizan estrategias que motiven a la ciudadanía a participar, como se ha demostrado al analizar los muy raros comentarios recibidos en peticiones" (Pérez-Escolar et al., 2020, p. 14).

Carrancio Pasilio (2020), quien estudia cinco peticiones en Change.org originadas por motivo del voto para ciudadanos uruguayos que residen en el exterior, ofrece una mirada más optimista sobre la plataforma. La intención del estudio es describir el género discursivo denominado petición digital, considerado como herramienta de la ciberciudadanía. El abordaje metodológico se sustenta en el análisis crítico de los géneros discursivos, que pretende detectar representaciones sobre los migrantes uruguayos que desean tener acceso al voto en el exterior. $\mathrm{Su}$ análisis invita a considerar esta plataforma como un espacio alternativo de expresión ciudadana, donde se pueden encontrar rasgos performativos diferentes a los presentes en las peticiones legislativas tradicionales.

Kirik et al. (2021) se interesan por estudiar las campañas enfocadas en las firmas digitales, una de las estrategias más utilizadas del activismo digital. Su artículo reviste de importancia en esta revisión de la literatura, ya que al discutir el caso de Change.org, buscan determinar cómo ha evolucionado el activismo digital a través de campañas de firmas, e intentan dilucidar cómo éstas afectan hechos y eventos. La mirada de la investigación está puesta en quienes participan de la firma de las peticiones
Change.org de Turquía. A través de una serie de encuestas a 407 usuarios, los investigadores concluyen que para esta muestra de usuarios, prevalece un bajo nivel de confianza en el éxito de las peticiones en línea, así como en el logro de las metas que se proponen (sólo $14 \%$ de los encuestados). A pesar de ello, el estudio también encontró que el $82 \%$ de los participantes dijeron que firman una petición con el propósito de contribuir a la solución del problema.

Los estudios sobre Change.org mencionados sucintamente en este apartado, y otros a los que es posible acceder (Calvo, 2017; Elnoshokaty et al., 2016; Halpin et al., 2018; Harrison et al, 2021; Huang et al., 2015; Marqués-Pascual, 2015) dan la pauta de que los procesos actuales de plataformización deben ser estudiados desde diversas perspectivas para poder conocer su impacto, no sólo en el plano tecnológico, sino también en la manera en que transforman estructuras económicas, educativas, y -desde el punto de vista que interesa en este estudio-, prácticas sociales y políticas.

Para realizar el estudio exploratorio se analizan las campañas de la plataforma Change.org que han recibido una mayor cantidad de adhesiones por parte de los usuarios de su comunidad virtual y se evalúan patrones de similitud y diferencias entre las causas que se apoyan en distintos puntos geográficos del mundo. La plataforma denomina a una campaña como victoriosa cuando la petición ha logrado un alto número de firmas o adhesiones únicas por parte de la comunidad digital. Debido a que las peticiones online no tienen un impacto vinculante en los sistemas políticos actuales, se entiende que la 
victoria ponderada por la plataforma respecto de sus campañas debe tener una lectura multifactorial que puede comenzar en la cantidad de adhesiones en el espacio digital, y podría terminar en el logro del objetivo planteado: "En 2019, decenas de miles de estas campañas generaron impacto, ya fuera informando e influenciando a la ciudadanía; obligando a los responsables de la toma de decisiones a tratar temas que de otro modo se habrían ignorado, o ayudando a cambiar la percepción que millones de personas tienen sobre su poder individual y colectivo" (Change.org, 2020, p. 9).

Los datos analizados fueron proporcionados por la plataforma (Change.org, 2018), en donde se indican las veinte peticiones que más adhesiones o firmas han conseguido a lo largo de su historia. El análisis se justifica especialmente por la alta cantidad de adhesiones obtenidas, sin embargo, la aproximación a estos datos es de tipo cualitativa, ya que se crean categorías y dimensiones que se infieren desde este tipo de abordaje.

Se plantean entonces los siguientes interrogantes: ¿qué rasgos muestran las campañas que movilizan a una cibercomunidad a ser más activa?, ¿cuáles son los intereses que se promueven desde estas peticiones que lograron tantos millones de adhesiones?, ¿qué tendencias señalan respecto de las motivaciones para la participación política en el territorio online?

Para ello, a partir de las peticiones de la plataforma que han tenido los índices más altos de promoción y adhesión a nivel global, se plantea como objetivo general examinar las temáticas que lograron un mayor apoyo por la cibercomunidad de
Change.org, y dos objetivos particulares: (O1) determinar los elementos de comunicación más relevantes de las campañas que han logrado la mayor cantidad de firmas en peticiones de la plataforma Change.org; e (O2) identificar diferencias y similitudes de los intereses que se defienden desde el activismo digital de las peticiones consideradas exitosas.

\section{Metodología}

La firma de peticiones como acción representativa de participación política tiene una larga tradición de estudio en el territorio offline. Las adhesiones que se realizan a peticiones online son también relevantes para el análisis, en tanto que éstas representan "una de las formas de democracia electrónica más avanzadas y sofisticadas, puesto que permiten una mejor y más rápida colaboración entre los usuarios, y suponen una mayor influencia de las demandas ante los responsables políticos" (Calvo, 2016, p. $105-$ 106).

En este artículo se analizan las veinte campañas más exitosas de la plataforma digital de peticiones ciudadanas Change.org, seleccionadas por la amplia adhesión que obtuvieron. El corpus está compuesto por aquellas victorias que, desde el surgimiento de la plataforma, generaron la mayor adhesión y apoyos en su comunidad online a nivel global. Estas campañas pueden observarse en la Tabla 1. 


\section{Tabla 1}

Campañas exitosas por orden de mayor cantidad de adhesiones

\begin{tabular}{|c|c|c|c|}
\hline Fecha & $\begin{array}{l}\text { Número de } \\
\text { firmas o } \\
\text { adhesiones }\end{array}$ & Tema / Contenido & URL \\
\hline $16 / 11 / 2016$ & $\begin{array}{c}4,917,998 \\
\text { (petición cerrada) }\end{array}$ & Movilización a votantes de Hillary Clinton & http://www.change.org/p/8736722 \\
\hline $15 / 06 / 2017$ & $\begin{array}{c}3,567,012 \\
\text { (petición abierta) }^{\mathrm{a}}\end{array}$ & $\begin{array}{l}\text { Movilización para cancelar un festival de carne de } \\
\text { perros en China }\end{array}$ & http://www.change.org/p/1539470 \\
\hline $14 / 12 / 2017$ & $\begin{array}{c}2,516,379 \\
\text { (petición abierta) }^{\mathrm{b}}\end{array}$ & $\begin{array}{l}\text { Movilización en defensa de la neutralidad en } \\
\text { Internet }\end{array}$ & http://www.change.org/p/11735314 \\
\hline 03/04/2016 & $\begin{array}{c}2,173,122 \\
\text { (petición abierta) }^{\mathrm{c}}\end{array}$ & $\begin{array}{l}\text { Movilización por la liberación de una ciudadana } \\
\text { inglesa presa en Irán }\end{array}$ & http://www.change.org/p/6989030 \\
\hline $20 / 11 / 2016$ & $\begin{array}{c}1,899,722 \\
\text { (petición abierta) }^{\mathrm{d}}\end{array}$ & $\begin{array}{l}\text { Movilización para cancelar un festival de carne de } \\
\text { perros en China }\end{array}$ & http://www.change.org/p/13268442 \\
\hline $25 / 04 / 2018$ & $\begin{array}{c}1,649,842 \\
\text { (petición cerrada) }\end{array}$ & Movilización para prohibición de jaulas para cerdos & http://www.change.org/p/13000945 \\
\hline $16 / 11 / 2017$ & $\begin{array}{c}1,578,984 \\
\text { (petición abierta) }^{\mathrm{e}}\end{array}$ & Movilización para evitar el tráfico de marfil & http://www.change.org/p/1 \\
\hline 26/07/2018 & $\begin{array}{c}1,269,951 \\
\text { (petición abierta) }^{\mathrm{f}}\end{array}$ & $\begin{array}{l}\text { Movilización para conocer la "palabra final" } \\
\text { usuarios sobre el Brexit. Final say campaign }\end{array}$ & http://www.change. \\
\hline $08 / 11 / 2018$ & $\begin{array}{c}1,043,716 \\
\text { (petición abierta) }^{\mathrm{g}}\end{array}$ & $\begin{array}{l}\text { Movilización por la retransmisión de un spot que } \\
\text { denunciaba el uso del aceite de palma, hace } \\
\text { referencia a la muerte de los orangutanes }\end{array}$ & http://www.change.org/p/13854341 \\
\hline $20 / C$ & $\begin{array}{c}942,288 \\
{\text { (petición abierta })^{\mathrm{h}}}\end{array}$ & $\begin{array}{l}\text { n quirúrgica } \\
\text { inos }\end{array}$ & http://www.change.org/p/13039212 \\
\hline $07 /$ & $\begin{array}{c}919,413 \\
\text { (petición abierta) }^{\mathrm{i}}\end{array}$ & $\begin{array}{l}\text { para cancelar un festival de carne de } \\
\text { ina }\end{array}$ & http://www.change.org/p/10422950 \\
\hline 01/ & $\begin{array}{c}767,787 \\
(\text { petición abierta) }\end{array}$ & $\begin{array}{l}\text { Movilización para evitar la continuidad de estudios } \\
\text { en perros labradores }\end{array}$ & http://www.change.org/p/12585910 \\
\hline 18 & $\begin{array}{c}577,924 \\
\text { (petición abierta) }^{\mathrm{k}}\end{array}$ & Movilización en defensa de los inmigrantes & http://www.change.org/p/13235420 \\
\hline $16 / 0$ & $\begin{array}{c}561,656 \\
\text { (petición cerrada) }\end{array}$ & $\begin{array}{l}\text { Movilizaci } \\
\text { tubería par }\end{array}$ & http://www.change.org/p/6814883 \\
\hline $07 / 05 / 2018$ & $\begin{array}{c}549,969 \\
\text { (petición abierta) }^{1}\end{array}$ & $\begin{array}{l}\text { Movilización para que Puerto Rico pueda recibir } \\
\text { ayuda humanitaria luego de un Huracán }\end{array}$ & http://www.change.org/p/12362338 \\
\hline $19 / 01 / 2018$ & $\begin{array}{c}543,828 \\
\text { (petición cerrada) }\end{array}$ & $\begin{array}{l}\text { Movilización para que un Ayuntamiento ayude a un } \\
\text { veterano de guerra británico }\end{array}$ & http://www.change.org/p/12915141 \\
\hline $10 / 10 / 2018$ & $\begin{array}{l}456,618 \\
\text { (petición abierta) }^{\mathrm{m}}\end{array}$ & Movilización para proteger a erizos & ://www.change.c \\
\hline $24 / 03 / 2018$ & $\begin{array}{c}424,380 \\
\text { (petición abierta) }^{\mathrm{n}}\end{array}$ & $\begin{array}{l}\text { Movilización para el control de uso y tenencia de } \\
\text { armas }\end{array}$ & http://www.change.org/p/13039151 \\
\hline 08/10/2018 & $\begin{array}{c}310,792 \\
\text { (petición cerrada) }\end{array}$ & $\begin{array}{l}\text { Movilización para defender la Opera House de que } \\
\text { se convierta en un espacio comercial y no cultural }\end{array}$ & http://www.change.org/p/13640368 \\
\hline $20 / 03 / 2018$ & $\begin{array}{c}162,411 \\
(\text { petición abierta) }\end{array}$ & $\begin{array}{l}\text { Movilización para crear un fondo nacional de } \\
\text { desastres y pueda atender las necesidades de los } \\
\text { campesinos que están sufriendo una sequía }\end{array}$ & http://www.change.org/p/13405403 \\
\hline \multicolumn{4}{|c|}{$\begin{array}{l}\text { Nota. A datos de } 2021 \text { las peticiones cuentan con las siguientes cantidades de firmas: }{ }^{\mathrm{a}} 4,101,117 ;{ }^{\mathrm{b}} 2,523,021 ;{ }^{\mathrm{c}} 3,548,655 ;{ }^{\mathrm{d}} \\
2,908,050 ;{ }^{\mathrm{e}} 1,653,468 ;{ }^{\mathrm{f}} 1,349,065 ;{ }^{\mathrm{g}} 1,083,319 ;{ }^{\mathrm{h}} 941,539 ;{ }^{\mathrm{i}} 985,515 ;{ }^{\mathrm{j}} 1,082,085 ;{ }^{\mathrm{k}} 863,948 ;{ }^{\mathrm{l}} 549,835 ;{ }^{\mathrm{m}} 978,236 ;{ }^{\mathrm{n}} 424,575 ;{ }^{\circ} \\
211,142 . \\
\text { Fuente: Change.org (2018). }\end{array}$} \\
\hline
\end{tabular}

Global Media Journal México, 18(34), 111-136, enero - junio 2021. 
Se considera que las victorias más exitosas a nivel mundial, catalogadas como tales por la plataforma debido a la alta cantidad de firmas según datos ofrecidos por responsables de Change.org, pueden ser indicios para conocer qué tipo de temáticas movilizan a la ciudadanía en este espacio virtual. El estudio también se justifica por intentar aportar a las investigaciones que observan el activismo en una plataforma privada y con fines lucrativos como es
Change.org (Calvo, 2016; Elnoshokaty et al., 2016; Halpin et al., 2018; Huang et al., 2015; MarquesPascual, 2015; Mellon et al., 2017). Los datos no se encuentran disponibles públicamente, de modo tal que fueron solicitados a miembros de la plataforma. Las peticiones que se analizan son aquellas consideradas exitosas en la historia de Change.org a diciembre de $2018^{3}$.

\section{Tabla 2}

Categorías y dimensiones de análisis

\begin{tabular}{|c|c|c|}
\hline Categoría & & Dimensiones \\
\hline Cantidad de firmas o adhesiones & \multicolumn{2}{|c|}{ Aspecto fáctico } \\
\hline País de la petición & \multicolumn{2}{|c|}{ Aspecto geográfico } \\
\hline Temática de la petición & \multicolumn{2}{|r|}{$\begin{array}{l}\text { Política (responsabilidad política, derechos ciudadanos) } \\
\text { Denuncia (derechos de los animales, derechos ambientales) } \\
\text { Social (otras causas sociales no políticas) } \\
\text { Cultural (defensa de espacios culturales, defensa de la cultura) } \\
\text { Otros }\end{array}$} \\
\hline Quién origina la petición & \multicolumn{2}{|c|}{$\begin{array}{l}\text { ONG } \\
\text { ciudadano/a particular } \\
\text { Otros agentes }\end{array}$} \\
\hline A quién va dirigida & \multicolumn{2}{|c|}{$\begin{array}{l}\text { Primer ministro o presidente } \\
\text { Miembros del Congreso o del Poder Legislativo } \\
\text { Otros representantes del Poder Ejecutivo } \\
\text { Entidades Reguladoras } \\
\text { Otras instituciones públicas } \\
\end{array}$} \\
\hline \multirow[b]{2}{*}{ Utilización de imágenes } & \multicolumn{2}{|l|}{ No } \\
\hline & & $\begin{array}{l}\text { Denotada } \\
\text { Connotada } \\
\end{array}$ \\
\hline \multirow[b]{2}{*}{$\begin{array}{l}\text { Deriva a las redes sociales de quien } \\
\text { origina la petición }\end{array}$} & No & \\
\hline & $\mathrm{Si}$ & $\begin{array}{l}\text { Facebook } \\
\text { Twitter } \\
\text { Blog } \\
\text { Otras plataformas }\end{array}$ \\
\hline
\end{tabular}

3 En las peticiones originales las campañas están en inglés, la traducción al castellano está hecha por parte las autoras del artículo.

Global Media Journal México, 18(34), 111-136, enero - junio 2021. 
El método empleado en esta investigación es el estudio de caso y el análisis de contenido cualitativo. El corpus se compone de las campañas que han recibido una mayor cantidad de adhesiones o firmas a lo largo de la historia de la plataforma. En esta porción de peticiones se realiza un abordaje cualitativo sobre su contenido. Las categorías construidas a partir de la observación se operacionalizan de manera inferencial. El abordaje permite extraer las principales características de los diferentes tipos de peticiones de la plataforma desde el análisis de ejemplos concretos (Eisenhardt, 1989; Simons, 2011) y son analizadas desde el enfoque teórico planteado.

\section{Resultados}

Para conocer las temáticas y técnicas que utilizan las campañas exitosas que movilizan a la cibercomunidad de Change.org, se observó en primera instancia cuáles son los países desde donde se promocionaron peticiones con la mayor adhesión en la historia de la plataforma. Estados Unidos lidera la movilización del ciberactivismo en la comunidad, le siguen Reino Unido y Australia. A pesar de que Estados Unidos y Reino Unido se encuentran en el primer y cuarto puesto con mayor cantidad de usuarios de la plataforma, respectivamente, y mantienen su liderazgo a la hora de analizar las

\footnotetext{
${ }^{4}$ Halpin et al. (2018) indican que el alto uso de Change.org en ese país se debe entre otros factores a que en Australia no cuentan con plataformas específicas creadas por el
}

Para el estudio se implementó una plantilla de análisis de contenido que facilita la exploración en profundidad y la obtención de un conocimiento cualitativo sobre las categorías y sus dimensiones. Tomando cada campaña como una unidad de análisis, se observa el modo en que se da la expresión de las categorías (Tabla 2).

La identificación de cómo se expresan estas categorías pretenden componer un abordaje analítico que se inspira en estudios sobre plataformas como los de Feenstra y Casero-Ripollés (2014) pero para el análisis de una plataforma privada, comercial y con fines de lucro como es Change.org.

peticiones exitosas y su procedencia. Al cotejar estos datos con la cantidad de usuarios, llama la atención que Australia está muy por debajo en cantidad de usuarios, pero es el tercer país que se instala como generador de peticiones exitosas ${ }^{4}$.

En segunda instancia, es relevante conocer los elementos comunes o diferentes que conforman cada campaña exitosa. Para ello, se ha realizado una observación e identificación de los contenidos que propone cada petición de modo particular. Los datos muestran que la gran mayoría de las peticiones exitosas buscan presionar a los representantes del poder ejecutivo, ya sea presidente, primer ministro/a, responsables de ministerios de gobierno e incluso, embajadores. Muy por detrás de estos, las peticiones

gobierno o la ciudadanía para canalizar peticiones que terminan encontrando un espacio en Change.org. 
que buscan presionar a senadores y diputados para que puedan gestionar cambios, a entidades reguladoras, a instituciones públicas como la Universidad y a otros actores, tienen una baja expresión en el corpus analizado. Se puede afirmar que las campañas exitosas de la plataforma buscaron conectar a los ciberactivistas con las más altas esferas del poder político.

El elemento vinculado al origen de la petición es relevante porque sugiere desde dónde se busca defender los intereses que cada petición representa. Los datos ratifican que fue el colectivo representado por la ciudadanía -aparentemente no institucionalizada- en Change.org quienes más han originado peticiones que lograron una amplia adhesión. Le siguen las originadas por organizaciones no gubernamentales (ONGs), que en menor medida, promocionaron peticiones que fueron exitosas, y por último, los datos muestran que otras peticiones exitosas fueron iniciadas por periodistas, blogs personales no adheridos a entidades institucionales y por la propia plataforma. En este último punto, sería interesante pensar un estudio que pueda cruzar datos con una posible intervención de parte de Change.org para mostrar a sus usuarios este contenido de manera preferencial (Finley, 2013).

En cuanto a los recursos de comunicación, el complemento de la imagen es frecuentemente utilizado en estas peticiones exitosas. También se observó la utilización de videos, pero en un grado mucho menor. Respecto de la retórica de las imágenes (Barthes, 1992) utilizadas en estas campañas, es frecuente que sean de tipo denotativo, es decir, el componente visual acompaña al mensaje textual de manera literal y su interpretación no requiere una codificación adicional. Por citar algunos ejemplos, a continuación, en las Figuras 1 y 2 pueden observarse los casos de dos de las campañas analizadas. La primera tiene que ver con la denuncia de la utilización de jaulas para cerdos, y la segunda con la evitar que la Casa de la Ópera de Sídney sea convertida en un centro comercial.

Figuras 1 y 2

Imágenes denotativas en campañas de Change.org

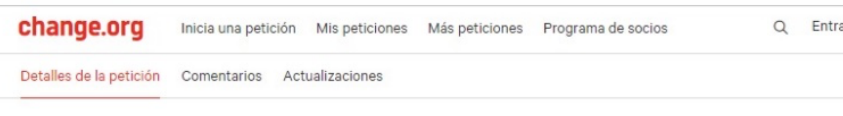

Ban pig cages

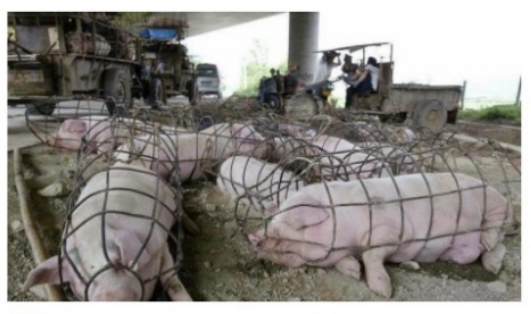

Fuente: Change.org \begin{tabular}{lllll} 
change.org Inicia una petición Mis peticiones Más peticiones Programa de socios & Q Entra \\
\hline Detalles de la petición Comentarios Actualizaciones & & \\
\hline
\end{tabular}

Defend Our Opera House: Support Louise Herron
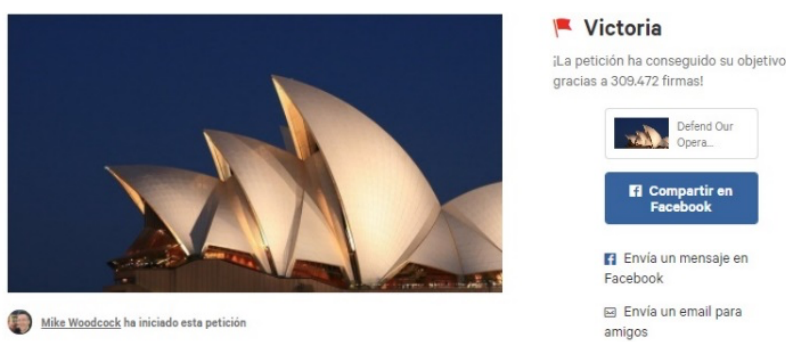
Encuentran menos espacio de expresión aquellas imágenes consideradas connotativas. Éstas son las que requieren algún tipo de abstracción de los mensajes textuales que las acompañan. Para comprender el significado de este tipo de imágenes en su contexto, la interpretación se remite a valores exofóricos, esto es, fuera del mensaje textual. En los casos señalados en las Figuras 3 y 4 se pueden observar dos ejemplos de este tipo de imágenes en campañas de Change.org. La primera está vinculada a la campaña contra la comercialización de marfil. La petición muestra una familia de elefantes disfrutando la vida en libertad, lo que apela al plano emocional y evoca a los valores de protección del reino animal. El segundo ejemplo funciona de manera similar; es una campaña que busca la liberación de una mujer detenida en Irán. La imagen muestra a la reclusa con su esposo y su hijo pequeño, y evoca el sentido de familia con el cual muchas personas pueden sentirse identificadas.

\section{Figuras 3 y 4}

Imágenes connotativas en campañas de Change.org

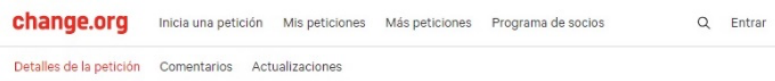

Ban elephant ivory and tusks from being imported into the U.S.

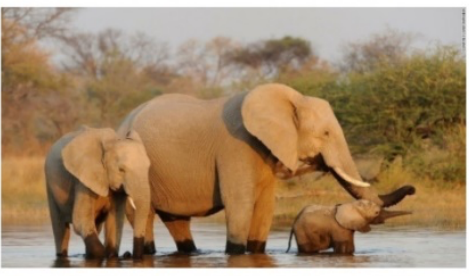

(3) Kostiben Me

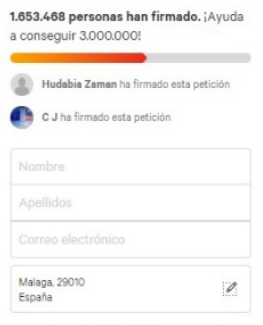

Fuente: Change.org

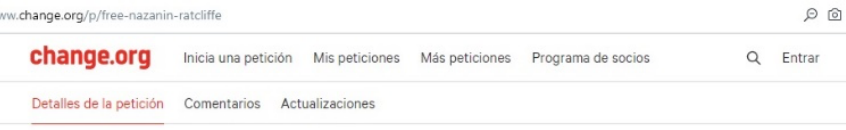

Free Nazanin Ratcliffe

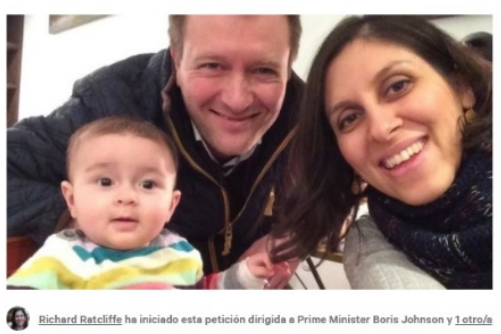

Respecto de la vinculación de la campaña con otros espacios dentro de Internet, es llamativo que se ha observado que en la mayoría de los casos las peticiones no están vinculadas a otras páginas web, ni tampoco a redes sociales. A pesar de que el contenido puede ser compartido una vez firmada la petición desde su origen, son pocos los casos que ofrecen la posibilidad de una viralización de los contenidos. Esto genera cierto grado de endogamia en las acciones de activismo digital de la comunidad de Change.org.

El nodo principal de análisis se encuentra en conocer las temáticas que proponen las peticiones más exitosas de la plataforma para obtener una guía acerca de cómo operan y en qué intereses se apoyan estas campañas para movilizar al ciberactivismo. Según los datos recabados, el mayor apoyo logrado en la historia de la plataforma tiene que ver con denunciar la responsabilidad política de los 
representantes del poder ejecutivo y legislativo, y con la defensa de los derechos de los animales. La reivindicación de los derechos de la ciudadanía se expresa en escasas ocasiones, y la defensa de los derechos ambientales también tiene una baja presencia a nivel comparativo.

Las peticiones que son consideradas victoriosas por países de mayor activismo digital presentan similitudes en el tipo de temáticas que abordan. Esto sugiere que, sin importar los índices culturales, económicos o sociales, existirían temáticas que movilizan de modo transversal a los ciudadanos. Se ratifica lo identificado por Feenstra y Casero-Ripollés (2014) respecto del modo en que la ciudadanía realiza un monitoreo cívico de sus representantes desde espacios digitales, ya que las temáticas con mayor número de firmas logradas en Change.org devienen de este tipo de contenidos que tienen como objetivo presionar a sus representantes. En esta plataforma -así como en otras que buscan un monitoreo explícito de los sistemas políticos- se evidencia un intenso interés por la acción cívica de monitoreo de la democracia (Keane, 2009).

Sin embargo, se observa que los derechos de los animales incitan a la comunidad a la participación en un grado importante, que iguala en cantidad de peticiones a las que tienen que ver con la institucionalidad de lo político. Este resultado despierta el interrogante para el estudio de las acciones políticas, ya que se observan campañas que emergen de intereses que se alejan del papel estrictamente político de defensa de derechos de la identidad, de la mujer, de la representación política o del medioambiente.

\section{Discusión y limitaciones}

Las características del estudio permiten generar una aproximación al tipo de temáticas que han logrado movilizar a una mayor cantidad de usuarios para que apoyen con su firma o - en algunos casos- con dinero a las campañas promocionadas en la plataforma privada Change.org.

La primera limitación que se puede remarcar es que el seguimiento de la movilización que provocaron estas peticiones no ha sido observado en otro espacio que no sea el de la plataforma Change.org, como puede ser Twitter o Facebook o plataformas de e-peticiones que tengan otros orígenes, distintos al privado. Esto quiere decir que el estudio también podría ampliarse a otros espacios digitales para conocer cómo se manifiestan las adhesiones y la movilización sobre estas temáticas en esos espacios. Estas otras relaciones también deben ser exploradas para dilucidar posibles acuerdos o negociaciones de actores en otros espacios (PazHerrera, 2015).

Sin embargo, en relación con los objetivos planteados, se considera que el estudio de caso que ofreció la plataforma permitió conocer similitudes y diferencias que constituyeron las peticiones de mayor adhesión en la comunidad digital, y se identificaron intereses manifiestos y latentes que movilizan a los usuarios a los que llegan los contenidos de esta plataforma en particular.

En segundo lugar, para los resultados del estudio se han considerado las campañas victoriosas de Change.org a partir de la variable mayor cantidad 
de firmas, rasgo desde donde la misma plataforma las define como tales. Esto significa que se han observado aquellas peticiones que a nivel mundial han recibido mayor cantidad de adhesiones, y este dato no fue cruzado con el hecho de si han logrado una modificación en el sistema político o estado de situación que pretendían transformar fuera del espacio digital, incluso, muchas de las peticiones indicadas en la Tabla 1 continúan abiertas. Ello abre el debate acerca del clickactivismo mencionado al inicio de este texto, millones de personas que a partir de tan sólo una firma tienen la ilusión de participar en el espacio público político. Es una limitación que no sólo radica en los estudios sobre Change.org, sino que, siguiendo a Gladwell, como se cita en Segerberg y Bennett (2011), el autor argumenta que

\begin{abstract}
[Gladwell] Caracterizó el activismo de los medios sociales en términos de lazos débiles y organización descentralizada horizontal y lo contrastó desfavorablemente con los lazos fuertes y la organización jerárquica centralizada que marcó las coyunturas clave en el Movimiento de Derechos Civiles. Gladwell (2010) concluyó que la acción en red digital no está bien equipada para lograr un cambio sistémico (p. 199).
\end{abstract}

Si bien puede señalarse como una limitación, se entiende que, como señalan Pérez-Escolar et al. (2020), “aunque el número de firmas no es el único factor de victoria o fallo de una campaña, puede servir para reconocer la popularidad de la petición en la plataforma" (p. 9). El abordaje propuesto se justifica debido a que el interés enunciado de la investigación buscó conocer aspectos relevantes de campañas que generan adhesión en la arena digital. Se seleccionó la plataforma para estudiar las peticiones que han logrado una adhesión considerable por su fortaleza, en tanto que tiene presencia en 196 países, y las veinte mayores victorias representaban una saturación del contenido que se buscaba identificar. Allí se examinaron las tendencias de defensa de intereses que proponían las campañas exitosas en el espacio digital.

Cabe aclarar que Change.org es una organización con fines de lucro y el modo en que utilizan la información dada por los usuarios sobre las temáticas que les interesan es luego utilizado como insumo para recomendar el apoyo en otras peticiones similares que en muchos casos están patrocinadas, es decir, que se muestran de manera privilegiada porque alguien pagó por estar en ese lugar de preferencia (Finley, 2013). Como diría Castells (1997), la red no está exenta del proceso capitalista, tanto en lo económico como en lo político, ya que la plataforma puede permitir aflorar peticiones menos relevantes que adquieren más visibilidad sólo por un factor económico. Se entiende que, como señala Papacharisi (2009), este debate se puede equilibrar evitando un enfoque determinista de las tecnologías digitales: "No es la naturaleza de las tecnologías en sí mismas, sino el discurso que los rodea, lo que guía cómo se apropian estas tecnologías por una sociedad" (p. 230). Es evidente que la intervención de la plataforma en la recopilación de información que luego tiene fines comerciales, le permite apuntalar su influencia desde la minería de 
datos. Es una línea de investigación que debe ser profundizada en otros estudios, gracias al camino que ya están abriendo otros investigadores (Calvo, 2016).

Las discusiones en torno al rol de Change.org como plataforma privada para canalizar peticiones ciudadanas continúan abiertas, pero desde el estudio realizado, se entiende que los resultados obtenidos abren otros debates sobre la emergencia de intereses que movilizan a la ciudadanía que van más allá de lo hasta ahora considerado estrictamente político. Este aspecto está en coincidencia con lo que Donaldson y Kymlicka (2011) señalaban cuando aseguraban que los derechos de los animales deben repensarse en el marco de una sociedad en la que muchas especies son actualmente co-ciudadanos.

En esta comunidad online la toma de la palabra y su defensa pone en disputa elementos que requieren de una observación en otros espacios, para considerar los rasgos que emergen de las acciones políticas en la arena digital; y que el clickactivismo debe ser considerado críticamente desde un prisma que comprenda que los modos de participación ciudadana se adaptan a los usos y apropiaciones de los actores que los instalan como parte de su vida cotidiana.

\section{Conclusiones}

Las campañas digitales analizadas apuntan a establecer bases de movilización sobre temas de carácter transversal, no supeditadas a aspectos económicos o culturales específicos de cada país.
Los países que tienen mayor cantidad de usuarios en la plataforma son aquellos que también logran una mayor movilización de parte de la comunidad ciberactivista. Se ha identificado, sin embargo, que en el caso de Australia, que se encuentra en el décimo lugar en cuanto a cantidad de usuarios en Change.org, se ha logrado generar campañas que lo posicionan como el tercer país en originar peticiones exitosas en la plataforma.

Además, desde el enfoque de los soportes de la comunicación de las peticiones se ha observado la importancia de la imagen para generar campañas exitosas. La gran mayoría de estas campañas utilizaron un soporte visual en la petición.

Respecto de las temáticas preponderantes entre las veinte campañas que más apoyo han recibido, un caso singular es el de la campaña contra un festival de carne canina en China, lo que provocó la generación de tres peticiones diferentes en la plataforma que han logrado altos índices de adhesión. Este dato es relevante porque permite considerar que las temáticas que movilizan a la comunidad online trascienden los espacios tradicionales de participación política, e invitan a considerar la construcción de la ciudadanía desde una perspectiva activa que demuestra un compromiso significativo con cuestiones que tienen que ver con aspectos más cercanos a los individuos. Es particularmente relevante que la plataforma es privada, pero de carácter abierto, y por ello, las peticiones no están predeterminadas por ninguna política del sitio web que permita o prohíba la promoción, difusión o apoyo de cualquier tipo de temática. 
Junto con Halpin et al (2018), se entiende que "tenemos una comprensión incompleta de cómo las plataformas de peticiones en línea están siendo utilizados por individuos para iniciar o apoyar campañas sobre temas importantes a ellos" (p. 429), por ello se ha intentado comenzar a ofrecer información y conocimiento sobre cómo operan las campañas con mayores adhesiones en la plataforma Change.org, teniendo en cuenta las limitaciones mencionadas en el apartado anterior. En este camino, se han detectado aspectos relevantes que deben ser observados desde distintos enfoques para refutarlos o ratificarlos.
Desde la perspectiva que se presenta, se considera a esta plataforma como un laboratorio apto para observar los intereses que movilizan a una comunidad digital activa, que busca una participación distinta en la esfera política. La movilización o el refuerzo (Norris, 2007) que ofrecen estos espacios digitales abiertos es una cuestión teórica que se debe profundizar para comprender cómo se desarrolla y evoluciona el activismo en la era digital, y es un camino de investigación que se debe construir con la observación, los datos, y desde diferentes enfoques.

\section{Referencias bibliográficas}

Alonso-Muñoz, L. y Casero-Ripollés, A. (2017). Transparencia y monitorización en el entorno digital. Hacia una tipología de las plataformas impulsadas por la ciudadanía. Revista Latina de Comunicación Social (72), 1351-1366. https://doi.org/10.4185/RLCS-2017-1223

Arias, G., y Jiménez-Gómez, I. (2020). Metodología para el estudio de las peticiones electrónicas sobre medioambiente. El caso de Change.org. En R. Eguizábal Maza y I. Jiménez-Gómez, Métodos y prácticas en el estudio de la comunicación (pp. 185-202). Fragua.

Barthes, R. (1992). Lo obvio y lo obtuso. Imágenes, gestos y voces. Ediciones Paidós.

Bennett, L., Breunig, C., y Terri, G. (2008). Communication and Political Mobilization: Digital Media and the Organization of Anti-Iraq War Demonstrations in the U.S. Political Communication, 25(3), 269-289. https://doi.org/10.1080/10584600802197434

Bimber, B. (2001). Information and political engagement in America: The search for effects of information technology at the individual level. Political Research Quarterly, 54(1). 53-67. https://doi.org/10.2307/449207

Calvo, D. (2016). Empresa privada y participación digital. OBETS, Revista de Ciencias Sociales, 11(1), 97-128. https://doi.org/10.14198/OBETS2016.11.1.05

Calvo, D. (2017). Características formales de las plataformas de peticiones online: sistemas públicos anglosajones, la opción privada en España. Área abierta. Revista de comunicación audiovisual y publicitaria, 17(2), 241-258. https://doi.org/10.5209/ARAB.51992

Global Media Journal México, 18(34), 111-136, enero - junio 2021. 
Carrancio Pasilio, N. (2020). Firma esta petición: discursos a favor y en contra del voto exterior para uruguayos en Change.org. Fórum Linguistico, 17(1), 4556-4571. https://doi.org/10.5007/19848412.2020v17n1p4557

Casero-Ripollés, A. (2017). Producing political content for web 2.0: Empowering citizens and vulnerable populations. El profesional de la información, 26(1), 13-19. https://doi.org/10.3145/epi.2017.ene.02

Castells, M. (1996). The Rise of Network Society. Blackwell Publishers Ltd.

Castells, M. (2000). La era de la información. Vol. II El Poder de la Identidad. Siglo XXI Editores.

Castells, M. (2002). La Transició a la Societat Xarxa. Ed. UOC.

Castells, M. (2007). Communication, Power and Counter-power in the Network Society. International Journal of Communication, (1), 238-266. https://bit.ly/2SQQzs1

Castells, M. (2009). Comunicación y poder. Alianza.

Castells, M. (2012). Redes de indignación y esperanza. Los movimientos sociales en la era de Internet. Alianza.

Chadwick, A. (2008). Web 2.0: New challenges for the study of e-democracy in an era of informational exuberance. I/S: A Journal of Law and Policy for the Information Society, 5(1), 9-42. https://bit.ly/3fd4vnu

Change.org. (18 de diciembre de 2018). Entrevista a Javier Sánchez, director de campañas y comunicación plataforma Change.org.

Change.org. (2020). Informe de impacto 2019. https://www.change.org/impact

Christensen, H. S. (2011). Political activities on the Internet: Slacktivism or political participation by other means? First Monday, 16(2). https://doi.org/10.5210/fm.v16i2.3336

Cotarelo, R., y Crespo, I. (Coords.) (2012). La comunicación politica y las nuevas tecnologías. Catarata.

Cotino-Hueso, L. (2011). Tratamiento jurídico y normativo de la democracia, participación y transparencia electrónicas: presente y perspectivas. En J. Barrat i Esteve y R. M. Fernández Riviera, Derecho de sufragio y participación ciudadana a través de las nuevas tecnologías (pp. 221-260). Civitas.

Dahlgren, P. (2018). La participación en línea en la esfera pública Las ambigüedades del afecto. InMediaciones de la comunicación, 13(1), 25-47. https://doi.org/10.18861/ic.2018.13.1.2824

Della Porta, D. y Diani, M. (2011). Los Movimientos Sociales. UCM-CIS.

Della-Porta, D. y Tarrow, S. (2005). Transnational Protest and Global Activism. Rowman and Littlefield.

Denning, D. E. (2001). Activism, Hacktivism, and cyberterrorism: The internet as a tool for influencing foreign policy. En J, Arquilla y D. F. Ronfeldt, Networks and Netwars: The Future of Terror, Crime, and Militancy (pp. 239-288). Rand. https://bit.ly/34K3fn3

Donaldson, S. y Kymlicka, W. (2012). Zoopolis: A Political Theory of Animal Rights. Oxford University Press.

Dumitrica, D. y Felt, M. (2020). Mediated grassroots collective action: negotiating barriers of digital activism. Information, $\quad$ Communication $\quad \& \quad$ Society, $\quad 23(13), \quad$ 1821-1837. https://doi.org/10.1080/1369118X.2019.1618891

Global Media Journal México, 18(34), 111-136, enero - junio 2021. 
Eisenhardt, K. (1989). Building Theories from Case Study Research. Academy of Management Review, 14(4), 532-550. https://doi.org/10.5465/AMR.1989.4308385

Elnoshokaty, A., Deng, S., y Kwak, D. (2016). Success Factors of Online Petitions: Evidence from Change.org, 49th Hawaii International Conference on System Sciences (HICSS), 1979-1985. https://doi.org/10.1109/HICSS.2016.249

Escobar, A. (1992). Reflections on 'Development': Grassroots Approaches and Alternative Politics in the Third World. Futures, 24(5), 411-436. https://doi.org/10.1016/0016-3287(92)90014-7

Espinoza, F. (2011). Pueblos indigenas: ¿Y después de la emergencia? Institute for Analysis of Change in History and Contemporary Societies (IACCHOS), Université Catholique de Louvain. https://bit.ly/3if2YAs

Feenstra R. y Casero-Ripollés, A. (2014). Democracy in the Digital Communication Environment: A Typology Proposal of Political Monitoring Processes. International Journal of Communication, 8, 2448-2468. https://bit.ly/3uOLhui

Fernández-Prados, J. (2012). Ciberactivismo: conceptualización, hipótesis y medida. Arbor. Ciencia, Pensamiento y Cultura, 188, 631-639. https://doi.org/10.3989/arbor.2012.756n4001

Finley, K. (26 de septiembre de 2013). Meet Change.org, the Google of Modern Politics. Wired. https://bit.ly/3z9OE2r

Geron, T. (2012). The Business Behind Change.org's Activist Petitions. Forbes. https://bit.ly/2PhzVO8

Glenn, C. (2015). Activism or “Slacktivism?”: Digital Media and Organizing for Social Change. Communication Teacher, 29(2), 81-85. https://doi.org/10.1080/17404622.2014.1003310

Gonzalez-Bailón, S., Borge-Holthoefer, J., Rivero, A., y Moreno, Y. (2011). The Dynamics of Protest Recruitment through an Online Network. Scientific Reports, (1). 1-7. https://doi.org/10.1038/srep00197

Grover, C. (2016). E-Petitions. Parliamentary Library \& Information Service. https://bit.ly/34fjKIU

Halpin, D., Vromen, A., Vaughan, M., y Raissi, M. (2018). Online petitioning and politics: the development of Change.org in Australia. Australian Journal of Political Science, 53(4), 428-445. https://doi.org/10.1080/10361146.2018.1499010

Harrison, T., Dumas, C., DePaula, N., Fake, T., May, W., Atrey, A., Lee, J., Rishi, L., y Ravi, S. (2021). Exploring E-petitioning and media: The case of \#BringBackOurGirls. Government Information Quarterly (in press). https://doi.org/10.1016/j.giq.2021.101569

Hindman, M. (2009). The myth of digital democracy. Oxford University Press.

Howard, P. (2005). Deep Democracy, Thin Citizenship: The Impact of Digital Media in Political Campaign Strategy. The annals of the American Academy of Political and Social Science, 597(1), 153-170. https://doi.org/10.1177/0002716204270139

Global Media Journal México, 18(34), 111-136, enero - junio 2021. 
Huang, S., Suh, M., Mako-Hill, B., y Hsieh, G. (2015). How Activists are Both Born and Made: An Analysis of Users on Change.org. Proceedings of the 33rd Annual ACM Conference on Human Factors in Computing Systems, 211-220. https://doi.org/10.1145/2702123.2702559

Inglehart, R. (1997). Modernization and postmodernization: Cultural, Economic and Political Change in 43 Societies. Princeton University Press.

Jenkins, H. (2006). Convergence culture: Where old and new media collide. New York University Press.

Jordan, T. (2002). ACTIVISM! Direct Action, Hacktivism and the Future of Society. Reaktion Books.

Keane, J. (2009). The life and death of Democracy. Simon y Schuster.

Kirik, A. M., Çetînkaya, A., y Kursun, A. K. (2021). Digital activism in the contexts of social movements: the case of Change.org. En S. Karadogân Doruk, S. Mengü y E. Ulusoy, Digital Siege (pp. 297-324). Istambul University Press. https://bit.ly/3cg9naU

Klotz, R. (2007). Internet campaigning for grassroots and Astroturf support. Social Science Computer Review, 25(1), 3-12. https://doi.org/10.1177/0894439306289105

Koenig, A. y McLaughlin, B. (2018). Change is an emotional state of mind: Behavioral responses to online petitions. New media \& society, 20(4), 1658-1675. https://doi.org/10.1177/1461444817689951

Kristofferson K., White K., y Peloza J. (2014) The nature of slacktivism: how the social observability of an initial act of token support affects subsequent prosocial action. Journal of Consumer Research, 40(6), 11491166. https://doi.org/10.1086/674137

Lilleker, D., Tenscher, J., y Štetka, V. (2014). Towards hypermedia campaigning? Perceptions of new media's importance for campaigning by party strategists in comparative perspective. Information, Communication \& Society, 18(7), 747-765. https://doi.org/10.1080/1369118X.2014.993679

Lindner, R. y Riehm, U. (2009). Electronic petitions and institutional modernization. International Parliamentary E-Petition Systems in Comparative Perspective. eJournal of eDemocracy and Open Government, 1(1), 111. https://doi.org/10.29379/jedem.v1i1.3

Lizaso, I., Sánchez-Queija, I., Parra, Á., y Arranz, E. (2018). La participación social online y offline de estudiantes universitarios españoles. OBETS. Revista de Ciencias Sociales, 13(2), 547-567. https://doi.org/10.14198/OBETS2018.13.2.04

Lee, Y., y Hsieh, G. (2013). Does slacktivism hurt activism? The effects of moral balancing and consistency in online activism. CHI '13: Proceedings of the SIGCHI conference on human factors in computing systems, 811-820. ACM Press. https://doi.org/10.1145/2470654.2470770

Maer, L. (12 de mayo de 2010). Proposals for an e-petitions system for the House of Commons. House of Commons Library. https://bit.ly/310mEHa

Margetts, H., John, P., Hale, S., y Yasseri, T. (2015). Political Turbulence: How Social Media Shape Collective Action. Princeton University Press.

Global Media Journal México, 18(34), 111-136, enero - junio 2021. 
Marqués-Pascual, J. (2015). Los criterios de noticiabilidad como factor de éxito del clickactivismo. El caso de Change.org. Estudios sobre el Mensaje Periodístico, 21(2), 883-898. https://doi.org/10.5209/rev_ESMP.2015.v21.n2.50890

Mellon, J., Russon Gilman, H., Sjoberg, F. M., y Peixoto, T. (Julio de 2017). Gender and Political Mobilization Online: Participation and Policy Success on a Global Petitioning Platform. Ash Center Occasional Papers. Harvard Kennedy School: Ash Center for Democratic Governance and Innovation. https://bit.ly/3g7fDTn

Mendes, J. y Araújo, P. (2013). Os lugares (im) possíveis da cidadania. Estado e risco num mundo globalizado. Almedina.

Millard, P., Millard, K., Adams, C., y McMillan, S. (Junio de 2012). Transforming Government Through eParticipation: Challenges for eDemocracy [Ponencia]. Proceedings of the $12^{\text {th }}$ European Conference on e-Government. Barcelona, España. https://bit.ly/302EXDz

Minocher, X. (2019). Online consumer activism: Challenging companies with Change.org. New Media \& Society, 21(3), 620-638. https://doi.org/10.1177/1461444818803373

Montero, D. y Sierra, F. (2016). Videoactivismo y Movimientos Sociales. Gedisa.

Morozov E. (19 de mayo de 2009). The brave new world of slacktivism. Foreign Policy. https://bit.ly/3ffIch1

Morozov, E. (2012). Net Delusion: The Dark Side of Internet Freedom. Public Affairs.

Mouffe, C. (1999). El retorno de lo político. Paidós.

Mouffe, C. (2007). En torno a lo político. Fondo de Cultura Económica.

Mouffe, C. (2013). Agonistics: Thinking the World Politically. Verso.

Norris, P. (2001). Digital Divide? Civic Engagement, Information Poverty \& the Internet in Democratic Societies. Cambridge University Press.

Norris, P. (2002). Democratic Phoenix: Reinventing Political Activism. Cambridge University Press.

Norris, P. (2007). Political activism: New challenges, new opportunities. En C. Boix y C. Stokes (Eds.), The Oxford Handbook of Comparative Politics (pp. 628-652.). Oxford University Press.

Papacharissi, Z. (2002). The virtual sphere: the Internet as a public sphere. New Media \& Society 4(1), 9-27. https://doi.org/10.1177\%2F14614440222226244

Papacharissi, Z. (2009). The Virtual Sphere 2.0: The Internet, the Public Sphere and beyond. En A. Chadwick y P. Howard, Handbook of Internet Politics, (pp. 230-245). Routledge. https://doi.org/10.4324/9780203962541-24

Parigi, P. y Gong, R. (2014). From grassroots to digital ties: a case study of a political consumerism movement. Journal of Consumer Culture, 14(2), 236-253. https://doi.org/10.1177/1469540514526280 
Paz-Herrera, M. (2015). Redes transnacionales de organizaciones indígenas. Análisis del uso de las redes en conflictos socioambientales. Revista de Estudios Sociales, (55), 63-72. https://doi.org/10.7440/res55.2016.04

Pérez Escolar, M. (2019). Introspectiva de los diferentes arquetipos de ciberactivismo: desde el primitivismo digital hacia los formatos emergentes de protesta. En S. Morales Calvo, F. Vidal Auladell y M. Mut Camacho, Nuevo paradigma comunicativo: lo 2.0, 3.0 y 4.0 (pp. 353-368). Gedisa.

Pérez-Escolar, M., Tapia-Frade, A., y Lozano-Delmar, J. (2020). Cultural activism: A content analysis of popular culture petitions on Change.org. Anàlisi: Quaderns de Comunicació i Cultura, (63), 1-17. https://doi.org/10.5565/rev/analisi.3271

Ruiu, M. y Ragnedda, M. (2017) Empowering local communities through collective grassroots actions: The case of "No Al Progetto Eleonora" in the Arborea District (OR, Sardinia). The Communication Review, 20(1), 50-67, https://doi.org/10.1080/10714421.2016.1272274

Sabariego, J. (2016). Podemos y los recientes movimientos sociales globales en España: hipótesis para una propuesta de investigación desde la práctica. Chasqui. Revista Latinoamericana de Comunicación, (130), 259-273. https://bit.ly/3ie76Re

Salazar Torres, N. (2017). La comunicación digital en la movilización y la resistencia indígena de Colombia. Revista de Comunicación, 16(2), 252-264. https://bit.ly/3bFZmDJ

Sampedro, V. (2014). El cuarto poder en red. Icaria.

Scheufele, D. y Nisbet, M. (2002). Being a citizen online: New opportunities and dead ends. Harvard International Journal of Press/Politics, 7(3), 55-75. https://doi.org/10.1177\%2F1081180X0200700304

Segerberg, A. y Bennett, W. L. (2011). Social Media and the Organization of Collective Action: Using Twitter to Explore the Ecologies of Two Climate Change Protests. The Communication Review, 14(3), 197-215. https://doi.org/10.1080/10714421.2011.597250

Shirky, C. (2011). The political power of social media: Technology, the Public Sphere, and Political Change. Foreign Affairs, 90(1), 28-41. https://bit.ly/3ifRbSD

Shulman, S. (2005). The Internet still might (but probably won't) change everything: Stakeholder views on the future of electronic rulemaking. I/S: A Journal of Law and Policy for the Information Society, 1(1). https://bit.ly/3odJoFH

Sierra Caballero, F. (2020). Ciberactivismo y nuevos movimientos urbanos: la producción del nuevo espacio público en la política contemporánea. Revista Perspectivas de la Comunicación, 13(1), 177-202. https://doi.org/10.4067/S0718-48672020000100177

Simons, H. (2011). El estudio de caso: teoría y práctica. Morata.

Skoric, M. M. (2012). What is slack about slacktivism? En M. M. Skoric (Ed.), Methodological and Conceptual Issues in Cyber Activism Research (pp. 77-104). Asia Research Institute, National University of Singapore.

Global Media Journal México, 18(34), 111-136, enero - junio 2021. 
Treré, E. (2016). Del levantamiento zapatista al escándalo NSA: Lecciones aprendidas, debates actuales y futuros desafíos de la resistencia digital. En J. Candón Mena y L. Benítez Eyzaguirre, Activismo digital y nuevos modos de ciudadanía: Una mirada global (pp. 40-59). InCom-UAB Publicacions.

Van Dijck, J. (2013). The culture of connectivity: A critical history of social media. Oxford University Press. 